\title{
An Evaluation of Psychosocial Rehabilitation Facilities for Homeless Mentally Ill in India
}

Anish K R*

\section{Abstract}

Homelessness due to chronic mental illness has become a major burden for most of the resource poor countries. The Kerala State in India has witnessed the efforts from the faith based organizations and religiously oriented families in the care and rehabilitation of the homeless mentally ill. This paper explores the processes used by these facilities for the care and rehabilitation of homeless mentally ill. Data were collected from the chief functionary of rehabilitation facilities, persons with mental illness residing in the rehabilitation centers, and volunteer care providers using interview schedules for the study of rehabilitation processes and profile of chief functionary and care providers. Otehre tools were, WHO QoL to measure the quality of life and level of functioning scale and Global Assessment of Functioning Scale for measuring the functioning. The care providers' orientation to mental illness was assessed using Orientation to Mental Illness Scale (Prabhu, 1983). 65\% of the centers displayed above average patient care services whereas $25 \%$ had poor overall quality of patient care services. The residents showed moderate level of quality of life in the area of physical health, psychological health, social relationships and high level of quality of life in the

\footnotetext{
* Asst Professor of Social Work, Rajagiri School of Social Sciences, Kerala; anishkrk@gmail.com.
} 
domain of environment. The research has also identified several gaps in functioning of the facilities.

Keywords: Homeless mentally ill, Rehabilitation facilities, Rehabilitation outcomes

\section{Introduction}

Persons with severe mental disorders, such as schizophrenia and bipolar affective disorder, represent a heterogeneous group with different problems and varying levels of needs. Severe mental disorders figure among the ten leading causes of disability and burden in the world (WHO, 2001; WHO, 2004). More often, severe mental disorder tends to run a chronic course and has a devastating impact on the person's functioning. Due to this global impact, it affects not just the individual, but also his family and, in turn, the community at large. The deficiency in care facilities and family neglect, force many of the mentally ill to lead a life in the streets. Homelessness due to chronic mental illness has become a major burden for most of the resource poor countries. Homeless mentally ill individuals reflect the current situation in the society of the limited mental health care available in the public sector, lack of coordination of different caring groups, and the absence of welfare system to meet the needs of mentally ill individuals and their families (Sheth, H.C., 2005).

Rehabilitation facilities for homeless mentally ill in Kerala, India are largely managed by faith based organisations. Several individuals and families in Kerala have been involved in providing food, clothing, shelter, medicine and occupational therapy, free of cost for the homeless mentally ill. These are mainly charitable efforts sustained by the active support, in cash and kind, of the local community (Murali, 2002). However, though these facilities existed in the community for many years no attempts have been made to systematically review the modus operandi and outcomes. These services need an examination with regard to the quality of care (Murali, T, Rao K. 2004; Jacob, K. S. 2001). There is no scientific documentation on these types of rehabilitation facilities except few comments made in conferences and articles (Murali, 2002; Radhakrishnan, V.K. 2002). Kumar, K. V., Sekar, K., Murthy, R. S. 
(2003) documented an evaluation report of The Banyan, an organisation for the rehabilitation of homeless mentally ill women in Chennai.

Iyer, Rothmann, Vogler, and Spaulding (2005) discussed the need for comprehensive assessment of outcomes in rehabilitation with advances in treatments for severe mental illness. The outcome measures identified were symptoms, cognitive measures, functional measures, quality of life, goal attainment, patient satisfaction etc. The main use of outcome evaluation in psychiatric rehabilitation has been to demonstrate the effectiveness of programs and specific treatment interventions.

Ruggeri, M., Warner, R., Bisoffi, G., Fontecedro, L.(2001) discussed the merits of Qquality of life in the measurement of outcome in chronic mental illnesses. It can be used to measure the incremental improvement rather than cure; it takes account of a wide range of aspects of daily living. The QOL measures have shown success in comparing different circumstances and treatment conditions.

\section{Materials and Methods}

The study used a Program Evaluation design to collect/analyse (here the use of the right verb will depend on what you have used the PE design for) data. The evaluation included review of the rehabilitation processes and facilities, care providers knowledge and attitude towards mental illness and rehabilitation outcomes demonstrated by the residents residing in the centers measured as the quality of life and level of functioning. Data were collected from chief functionary of rehabilitation facilities, persons with mental illness residing in the rehabilitation centers, and volunteer care providers. 20 rehabilitation centers from 42 organisations registered with Kerala Federation of Care of the Mentally Disabled were selected using simple random sampling. The Chief Functionaries (16 men and 4 women, mean age: $51.9 \pm 12.24)$ of the centers were interviewed for data collection on rehabilitation facilities and rehabilitation processes adopted by the centers. All the chief functionaries were Christians and 14 of them were married. All the care providers available at the time of the visit 
were interviewed to assess their orientation to mental illness. 66 care providers (41 men and 25 women, mean age: $37.9 \pm 7.64$ ) responded to the interview. 10 residents (each fulfilling the inclusion and exclusion criteria were selected from each of the centers using simple random sampling. Data was collected from 181 residents (112 men and 69 women; mean age $38.62 \pm 9.63)$.

The participants were interviewed by the researcher using the following tools.

Interview Schedule for Rehabilitation Facilities: A structured interview schedule was prepared, pre-tested and utilized for the study. The tool gathered information regarding information relating to organization, profile of the person in charge, profile of physical infrastructure, staffing pattern, profile of services provided, profile of rehabilitation activities and other services.

Orientation to Mental Illness Scale (Prabhu, 1983): The 67- item scale measured the care providers' attitude towards mental illness in four domains viz. Causation, Perception of Abnormality, Treatment and Aftercare. The computed scores of the scale indicated the extent of unfavourable orientation held by individual, with higher scores indicting a more unfavourable orientation.

Level of Functioning Assessment - (5 point Lickert Scale): The functioning assessment assessed five dimensions - Community Living, Interpersonal Relationships, Psychological Functioning and Physical Functioning. The computed scores were calculated out of five, with higher scores indicating better functioning in the domain areas.

Global Assessment of functioning Scale (1994): The GAF was developed in the early 1990s to rate Axis V of DSM-IV. It provides a measure of overall functioning related to psychiatric symptoms. The scale is clinician rated on a 100-point scale based on all available information, with clear descriptions of each 10-point interval. The most widely used global function scale is the Global Assessment of Functioning (GAF) scale, which is incorporated into the DSM-IV TR. The GAF rates overall personal and social functioning. 
WHO Quality of Life Scale (WHOQOL-BREF): The WHOQOL-BREF instrument comprise 26 items that measure four broad domains: physical health, psychological health, social relationships, and environment. The WHOQOL-BREF is a shorter version of the original instrument. The computed score is transformed to be in the range of 1-100, with higher score indicating better quality of life in the sub domains.

The quantitative data gathered was analyzed using Predictive Analysis Software (PASW 17.0, SPSS 17.0). Statistical tests performed to analyze the data were descriptive Statistical measures: Percentage, Ratios Mean, Median and Standard Deviation.

\section{Results}

\section{Rehabilitation Facilities}

The rehabilitation centers rely on public donation as their main source of income and none of them charge any fees for the services. The centers have one room per 13 residents and one toilte per 12 residents (Figure 1).

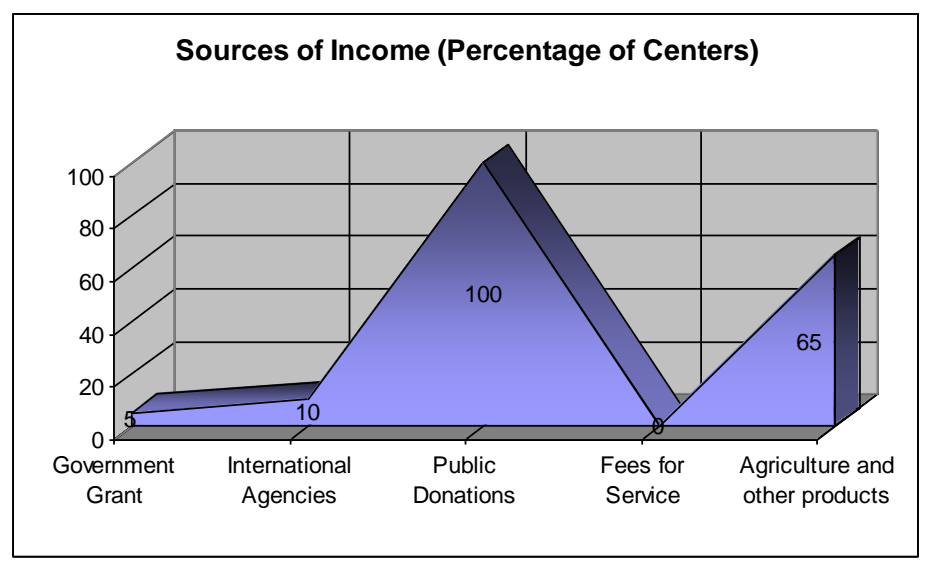

Fig.1 
The centers are manned by volunteers and recovered residents. Figure 2 depicts that the majority of the centers employ 1-5 staff and 6-10 volunteers. The centers have an average of 5 staff and 10 recovered residents for the activities.

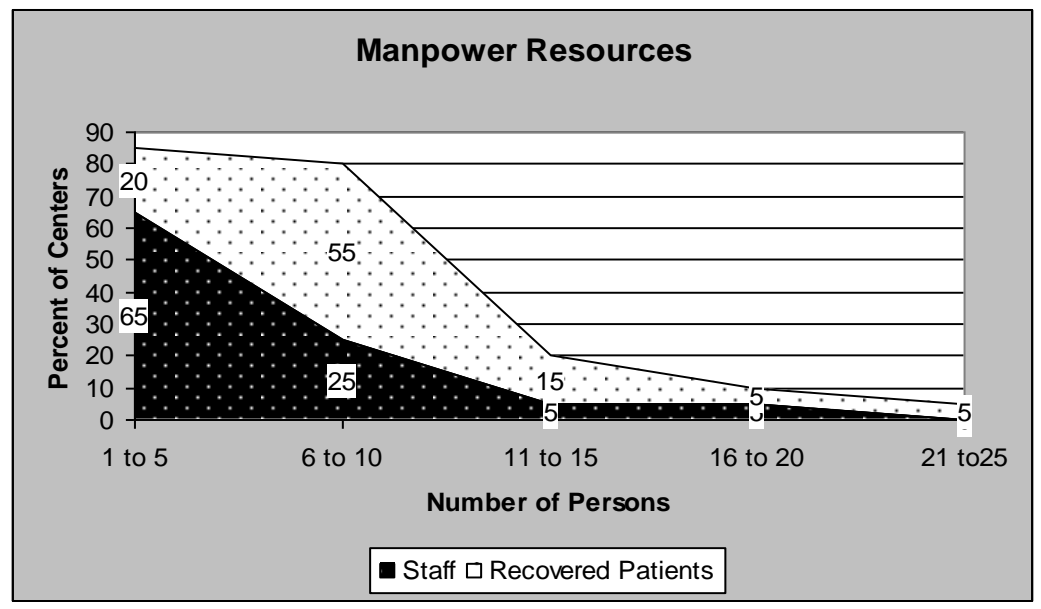

Fig. 2

Figure 3 showed that majority of the admissions to the centers were done by police and social agencies/ public.

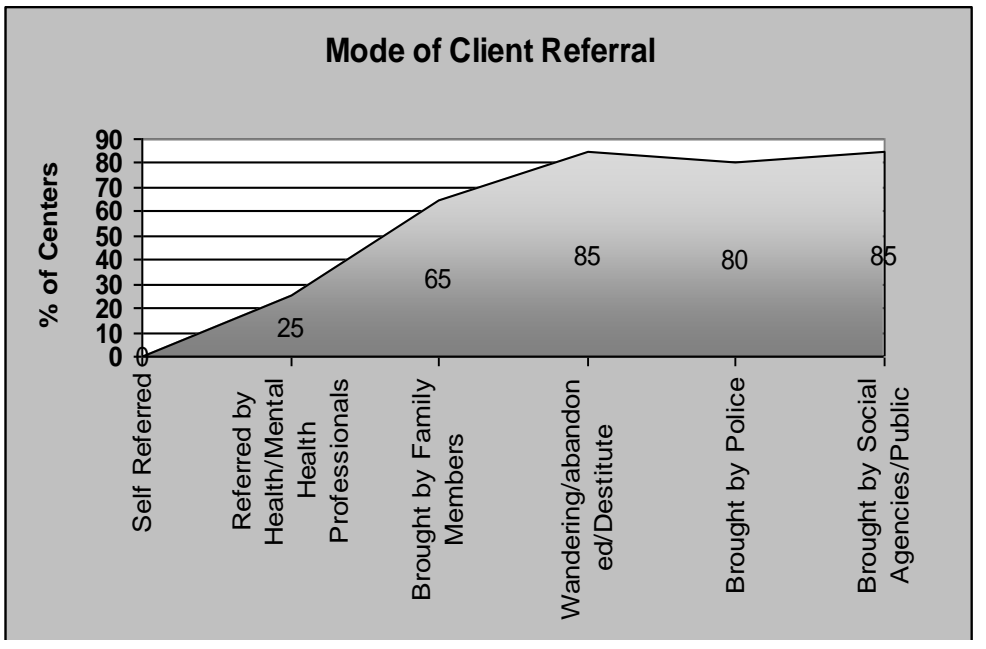

Fig. 3 
The rehabilitation centers catered to an average of 99 clients in total of which 63 were males and 36 were females. Some of the centers provided care exclusively to men or women. Out of 99 clients, centers served an average of 91 severely mentally ill (Table 1).

Table 1. Number of Clients Served

\begin{tabular}{|l|c|c|c|c|}
\hline \multicolumn{1}{|c|}{ Statistics } & Men & Women & Total & $\begin{array}{l}\text { Severely } \\
\text { Mentally ill }\end{array}$ \\
\hline $\begin{array}{l}\text { Mean number of clients served } \\
\text { by the centers }\end{array}$ & 63 & 36 & 99 & 91 \\
\hline Median & 58 & 15 & 84 & 82 \\
\hline Std. Deviation & 54.56 & 49.83 & 78.54 & 69.75 \\
\hline $\begin{array}{l}\text { Minimum Number of clients in } \\
\text { the centers }\end{array}$ & 0 & 0 & 12 & 11 \\
\hline $\begin{array}{l}\text { Maximum Number of clients in } \\
\text { the centers }\end{array}$ & 143 & 160 & 260 & 250 \\
\hline
\end{tabular}

\section{Rehabilitation Processes}

All the rehabilitation centers work as long stay homes, none are providing outpatient services, day care services and night hostel. 95 percent of the centers involve their members in routine activities, 65 percent involve the residents in vocational activities, 15 percent of the centers provide social skill training and none of them practice rehabilitation assessment, rehabilitation Planning or behavior modification techniques with their residents (Figure 4).

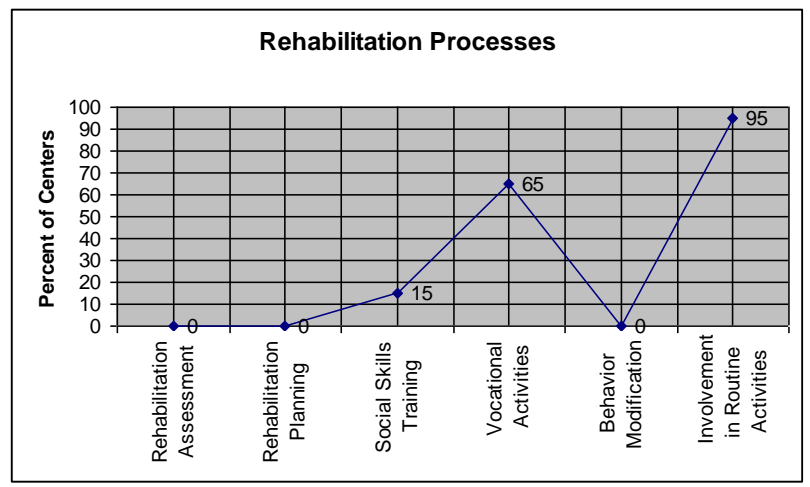

Fig. 4 
The rehabilitation activities include natural rehabilitation measures like dairy (65\%), Agriculture (55\%), Horticulture (45\%), and Poultry (40\%) (Figure 5 ).

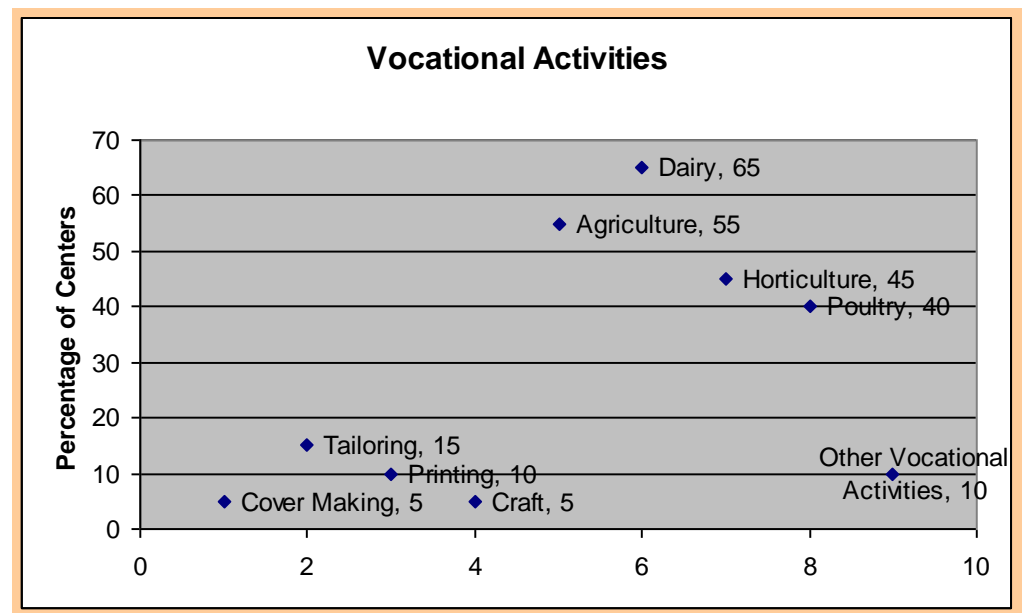

Fig. 5

* Multiple responses

Figure 5 pictorially depicts the type of vocational activities on the top region as the major vocational activities. The activities adopted were dairy, agriculture, horticulture and poultry. The percentage of centers adopted traditional vocational activities such as tailoring, craft, printing and cover making was very low. This indicated that the rehabilitation centers used vocational activities closer to the natural life of the residents. This is being substantiated by Mueser et al. (1997) who found that successful rehabilitation processes are close to the natural environment of the mentally ill persons. Further, these rehabilitation activities do not require trained instructors too. This has significance to the higher possibility of translating these skills to the life of the individuals after their discharge to community. These types of vocational activities are expected to bring out more productive outcomes of rehabilitation and sustained recovery, the evidence of which need to be explored further through a well planned longitudinal study.

The average monthly cost of care for the homeless residents is 985 rupees. 


\section{Quality of Patient Care Services}

The study explored the quality of patient care services through the measurement of seven parameters viz. 1) Rehabilitation processes, 2) Availability of structured schedule for residents, 3) Percentage of residents involved in productive activities, 4) Ratio of number of severely mentally ill to number used in rehabilitation activities, 5) Ratio of number of residents to number of rooms, 6) Ratio of number of residents to number of toilets, and 7) Ratio of number of residents to number of staff (volunteer staff plus recovered patients used as staff). The rehabilitation centers were rated based on the values obtained in the parameters in the rehabilitation section of the study converted to a six point scale ranging from Very Good to Very Poor. The researcher calculated the overall quality of patient care services from the seven parameters. The parameters were identified from quality parameters used in documents assessing mental health facilities (NHRC 1999, 2008, WHO 2005).

Table 2. Quality of Patient Care Services $(\mathbf{N}=\mathbf{2 0})$

\begin{tabular}{|l|c|c|c|c|c|c|}
\hline \multicolumn{1}{|c|}{$\begin{array}{l}\text { Quality of Patient } \\
\text { Care Services }\end{array}$} & $\begin{array}{c}\text { Very } \\
\text { Good }\end{array}$ & Good & Moderate & Satisfactory & Poor & $\begin{array}{c}\text { Very } \\
\text { Poor }\end{array}$ \\
\hline $\begin{array}{l}\text { Rehabilitation } \\
\text { Processes }\end{array}$ & 0 & 0 & 3 & 1 & 16 & 0 \\
\hline $\begin{array}{l}\text { Availability of } \\
\text { Structured Schedule } \\
\text { for residents }\end{array}$ & 5 & 0 & 13 & 0 & 0 & 2 \\
\hline $\begin{array}{l}\text { Percent of Residents } \\
\text { Involved in } \\
\text { productive activities }\end{array}$ & 4 & 3 & 2 & 5 & 3 & 3 \\
\hline $\begin{array}{l}\text { Number of SMI- } \\
\text { Number used in } \\
\text { rehab activity Ratio }\end{array}$ & 4 & 8 & 4 & 2 & 2 & 0 \\
\hline $\begin{array}{l}\text { Resident- Room } \\
\text { Ratio }\end{array}$ & 2 & 7 & 3 & 4 & 3 & 1 \\
\hline Resident-Toilet Ratio & 4 & 5 & 5 & 2 & 3 & 1 \\
\hline Resident-Staff Ratio & 8 & 8 & 2 & 2 & 0 & 0 \\
\hline $\begin{array}{l}\text { Overall Quality of } \\
\text { Patient Care Services }\end{array}$ & 4 & 4 & 5 & 2 & 4 & 1 \\
\hline
\end{tabular}


Table 2 and Figure 6 considering the seven parameters revealed that out of 20 centers studied four of the centers displayed Excellent overall quality of patient care services, Four were Very Good, Five were Good, Two were Moderate, Four were Poor and One was Very Poor. $($ Total $=20)$

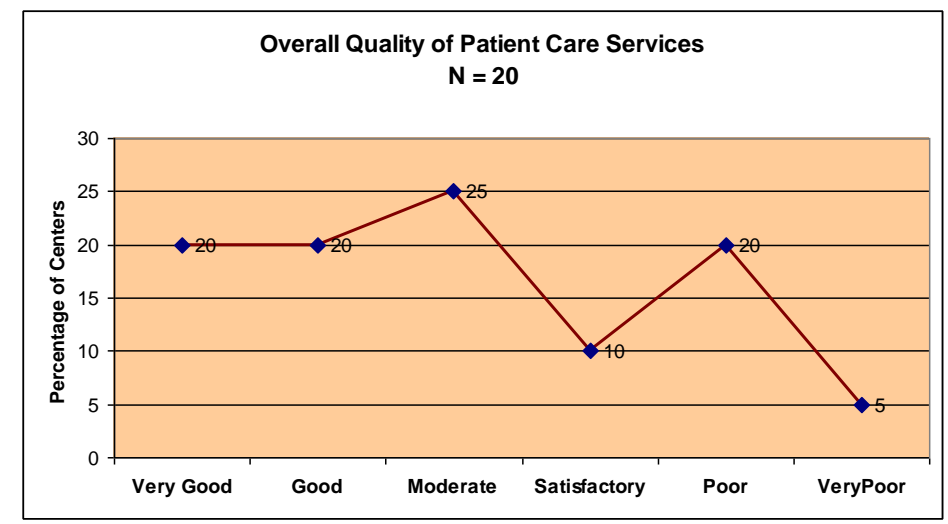

Fig. 6

Table 3 depicted the care providers' orientation to mental illness. The scores in all the domains revealed a Favourable orientation towards mental illness. The mean score of orientation to mental illness $2.25 \pm 0.24$ indicated Favourable orientation among the care providers.

Table 3. Orientation to Mental illness of the Care Providers

\begin{tabular}{|l|r|r|r|r|r|}
\hline Statistics & Causation & $\begin{array}{c}\text { Perception of } \\
\text { Abnormality }\end{array}$ & Treatment & $\begin{array}{l}\text { After } \\
\text { Care }\end{array}$ & $\begin{array}{c}\text { Orientation to } \\
\text { Mental Illness } \\
\text { Total }\end{array}$ \\
\hline $\mathrm{N}$ & 66 & 66 & 66 & 66 & 66 \\
\hline Mean & 2.48 & 2.01 & 2.30 & 2.23 & 2.25 \\
\hline $\begin{array}{l}\text { Std. } \\
\text { Deviation }\end{array}$ & .29 & .32 & .24 & .25 & .24 \\
\hline
\end{tabular}

\section{Rehabilitation Outcomes}

The rehabilitation outcomes of the residents were measured using patient satisfaction, quality of life and level of functioning as the outcome measures. 


\section{Patient Satisfaction}

Figure 7 depicted the client satisfaction assessed in three areas viz. overall satisfaction, satisfaction with physical facilities and care providers. The results indicated that majority of the residents were satisfied with the centers in all the areas of assessment. The physical facilities available in most of the centers were adequate and provided the residents a dignified place to live, compared to the precarious situations in the streets. The psychiatric and medical support helped most of the residents to ameliorate their symptoms. Women especially perceived the safety, once they were out of the acute phase of illness. Most of the care providers were voluntary and were motivated by non-financial reasons and considered the work as their vocation and not a job. Hence, the staff approaches were friendly and caring. These factors all could have contributed to the high level of satisfaction.

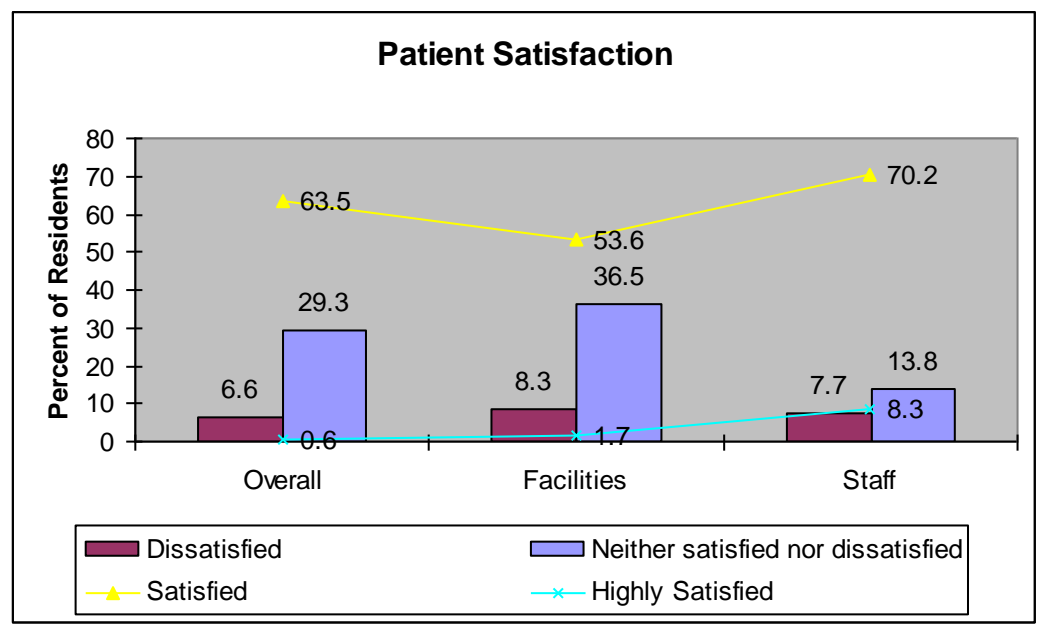

Fig. 7

\section{Quality of Life}

Table 4 depicted the quality of life of the residents. The assessment of quality of life of the residents revealed moderate level of quality of life in the area of physical health, psychological health, social relationships and high level of quality of life in the domain of environment. 
Table 4. Quality of Life of Residents

\begin{tabular}{|l|c|c|}
\hline Quality of Life Domains (Transformed scores) & Mean & Std. Deviation \\
\hline Domain 1 - Physical Health & 54.50 & 2.67 \\
\hline Domain 2 - Psychological Health & 47.30 & 3.06 \\
\hline Domain 3 - Social Relationship & 49.10 & 4.88 \\
\hline Domain 4 - Environment & 60.90 & 5.22 \\
\hline
\end{tabular}

The quality of life scores indicated that the residents have moderate levels of quality of life in three out of four domains of quality of life. The observations of Jeanette Hewitt (2007) substantiated the finding and reported that subjective quality of life of people with serious mental illness has been shown to be lower than in the general population.

\section{Level of Functioning}

The assessment of level of functioning (Figure 8) showed very low levels of functioning in the domain of community living, low levels of functioning in the domains of interpersonal relationship, psychological functioning (mood disturbance and psychotic symptoms), and within normal limits of functioning in psychological functioning (dangerous behaviour) and physical functioning.

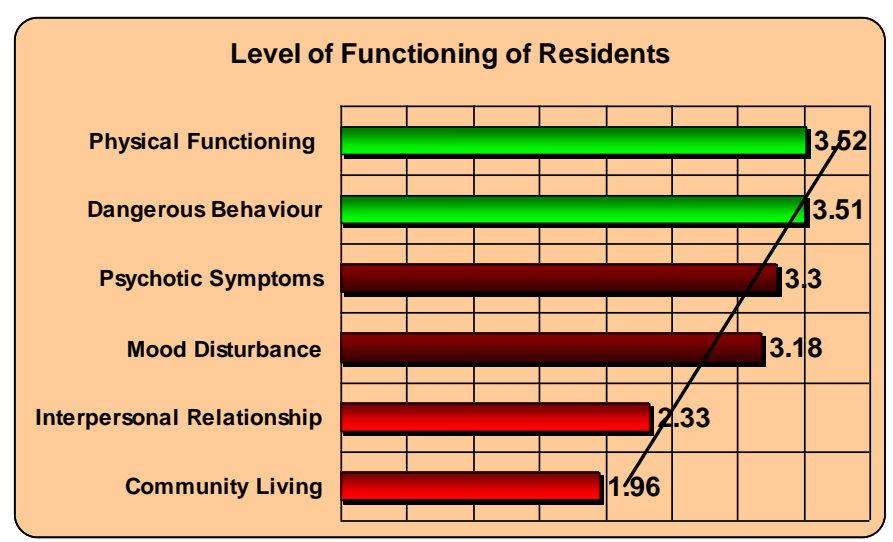

Fig. 8 


\section{Discussion}

Research studies and official documents in India documented the dearth of resources for caring for the mentally ill. The facilities for long term care are scarce in the context of large number of families unable or unwilling to give care to the severely mentally ill due to lack of resources. The voluntary initiatives of a group of individuals in the state of Kerala, seem to be relevant in this context, as a low cost community based rehabilitation model for homeless mentally ill (Santhosh, J, Anish, K.R, 2006).

The reports of National Human Rights Commission (NHRC, 1999, 2008) and other health review committees (Bhore Committee, Mudaliar Committee) consistently reported the scarcity of infrastructural and human resources for mental health care in India. The reports also discussed the limitations of the facilities for caring the mentally ill. The WHO, Mental Health Atlas (2005) reported that the psychiatric beds in India are grossly inadequate for the care of persons with severe mental illness. The relevance of these centers is discussed in this context of limited rehabilitation facilities and inadequate care facilities for homeless mentally ill in the country

The major discussion with regard to these organizations is their non-compliance with Mental health Act (1987) especially in the context of post Erwadi observations of the Supreme court (Orders of the Supreme Court in Civil Writ Petition No 334/2001 \& 562/2001). The comments about establishment and maintenance of private psychiatric hospitals are noteworthy in this context. "MHA is a proactive legislation to achieve the ideal minimum standards of mental hospitals but is difficult to implement pragmatically because of acute shortage of human resources" (Suresh, B.M., Nagaraja, D., 2008).

The Mental Health Act (MHA) (1987) has not laid much emphasis on rehabilitation centers but mentioned convalescent homes and the policy implies that the minimum standards applicable to psychiatric hospitals which deal with acutely disturbed patients with severe illness also apply to convalescent homes, where the focus is on rehabilitation and reintegration into the community. 
This has lead to a great deal of concern among private convalescent homes and rehabilitation centers operated mainly in the nongovernmental sectors whose aims and functions are distinct from psychiatric hospitals. It is a matter of debate whether these organizations should be brought under the purview of the Mental Health Act, or whether their monitoring should be brought under alternative Acts like the Rehabilitation Council of India Act (1992).

These centers act as models for caring homeless mentally ill which the government is not able to do due to several reasons. However, these centers do not have uniform protocol for functioning. Saraceno et al. (2007) while discussing the barriers to improvement of mental health services in low-income and middle-income countries recommended that community members without formal professional training and people who have mental disorders and their family members, need to partake in advocacy and service delivery. However, the standards of care need to be set and ongoing quality monitoring is to be facilitated by the state government and state mental health authority *. The concerned bodies could guide the operations of such centers through developing an operational guideline*. $\{$ The centers operated with the support of volunteers and recovered patients. The psychiatric care is performed by Psychiatrists and other mental health professionals were employed seldom.\}

95 percent of the centers admitted that wandering homeless mentally ill are either brought by police or public. Even when, they were brought by police, official procedures for admission like reception order (MHA, 1987) were not taken for the admission. This situation clearly draws the social relevance of such centers for the care of homeless mentally ill. The centers support the necessary basic needs of the homeless persons. The NHRC (2008) after reviewing the mental health facilities in the country commented that non-government organisations play an extremely important role in the absence of a formal or well-functioning mental health system, filling up the gap between community needs and available community services and strategies.

Most of the centers had insufficient planned rehabilitation activities. None of the centers performed rehabilitation assessment 
and planning. Though not very planned, majority of the centers utilized the services of the residents for the day to day functioning and routine activities. The vocational activities performed are largely natural like dairy, poultry, goat and cow rearing and agricultural activities. The advantage noted was that most of these activities did not require extensive supervision and highly skilled instructors. This also helps in translating their skills in to their life context after discharge from the center. This is highly relevant as stated in the principle of psychosocial rehabilitation suggested by IAPRS "Psychiatric Rehabilitation practices help people re-establish normal roles in the community and their reintegration into community life"(IAPRS, 1998).

The deficit in planned rehabilitation activities were attributed to absence of trained human resources, absence of an operational guideline for the functioning, poor skills of the existing staff and resource deficits for employing more staff. This circumstance again calls for capacity building of the staff available and developing clear operational guidelines for guiding the operations. While assessing the care providers' orientation to mental illness in four domains viz. causation, perception of abnormality, treatment and after care, it was found that the care providers in general have favourable orientation to mental illness in all the domains. This showed that the attitudes of the care providers were positive and they could be supported with organised capacity building programmes for enhancing their efficiency and effectiveness in working with persons with mental illness. The capacity building programmes would supplement in enhancing the quality of patient care services, which in turn would enhance the quality of life of residents.

The QoL scores of the residents showed moderate levels of quality of life in all domains of the QoL. The results are consistent with many other studies on QoL of mentally ill. The studies showed significant differences in quality of life of clinical and non-clinical groups (Murphy, H. and Murphy, E.K., 2006), greater QOL variability in patients with low function scores compared to those with medium and high function scores (Becker, T., et al. ,2005), quality of life was associated with decreased psychotic and 
depressive symptoms, reduced substance abuse, fewer days of homelessness, and increased social support, income, employment, and service use ( Lam, J.A. and Rosenheck, R. ,2000 ).

An evaluation study of The Banyan conducted among the resettled homeless mentally ill residents also showed below average quality of life in psychological, social and environment domains (Kumar, Sekar, Murthy, 2003). The quality of life was highly related to health of the person and duration of illness.

Level of functioning is found to be within normal limits in physical functioning and dangerous behaviour and is low in psychological functioning and very low in interpersonal relationship and community living. The research evidences substantiate these findings. Patients with schizophrenia had significantly greater disability in areas of communication, transportation, finance and shopping ( Klapow, et al., 1997), lower level of general functioning compared to general population (Goering, Paula, Lin, et al., 1996).

\section{Conclusion}

This study described the facilities for rehabilitation of homeless mentally ill, rehabilitation processes adopted, quality of patient care services, personal profiles of chief functionaries, care providers and residents and rehabilitation outcomes. This has emerged as the first literature on these types of innovative, low cost rehabilitation facilities for homeless mentally ill.

\section{References}

Anish, K. R. (2006). Quality Of Life and Level of Functioning as Rehabilitation Outcome of Chronic Mentally Ill. Paper presented during Oral Scientific Presentation of IX World Congress, World Association of Psychosocial Rehabilitation, Athens, Greece, 12-15, October.

Becker, T., et al. (2005). Needs and quality of life among patients with schizophrenia in five European centres: what is the impact of global functioning scores?, Social Psychiatry and Psychiatric epidemiology, 40(8): 628-634. DOI: 10.1186/1471-244X-13-99.

Bhaskaran, K.. (1970). The unwanted patient. Indian Journal of Psychiatry, 12, 31 -12 
Goering, Paula, Lin, et al., (1996). Psychiatric disability in Ontario, Canadian Journal of Psychiatry, 41 (9): 564-571. DOI. 10.4103/00195545.117129

International Association of Psychosocial Rehabilitation Services [IAPSRS] Committee on Publications (1998). Chapter 1: what is psychiatric rehabilitation?: In Spaniol, L., Brown, M.A., Blankertz, L., Burnham, D.J., Dincin, J., Furlong-Norman, K., Nesbitt, N. Ottenstein, P., Prieve, K., Rutman, I.., Zipple, A. (eds.), An Introduction to Psychiatric Rehabilitation. Columbia, Maryland: IAPSRS.

Iyer, S., Rothmann, T. L., Vogler, J. E., and Spaulding, W. D., (2005). Evaluating Outcomes of Rehabilitation for Severe Mental Illness. Rehabilitation Psychology, 50 (1): 43-55. DOI. 10.1037/a0030774

Jacob, K. S. (2001). Community care for people with mental disorders in developing countries. Problems and possible solutions. British Journal of Psychiatry, 178, 296-298. doi/10.1192/bjp.178.4.296.

Jeanette Hewitt (2007). Critical evaluation of the use of research tools in evaluating quality of life for people with schizophrenia. International Journal of Mental Health Nursing, 16 (1) , 2-14.

Killaspy, H, Ritchie, C.W., Greer, E. \& Robertson, M. (2004). Treating the homeless mentally ill: does a designated inpatient facility improve outcome?, Journal of Mental Health, 13(6), 593-599. doi/10.1080/09638230400017038.

Kim, T. Mueser., Robert, E. Drake., Gary, R. \& Bond. (1997). Recent Advances in Psychiatric Rehabilitation for Patients with Severe Mental Illness., Harward Review of Psychiatry, 5(3): 123-137. DOI: $10.1080 / 10673220802167782$

Klapow, J.L., Evans, J., Patterson, T.L., Heaton, R.K., Koch, W. L. \& Jeste, D.V. (1997). Direct assessment of functional status in older patients with Schizophrenia.

Kumar, K. V., Sekar, K., \& Murthy, R. S. (2003). Making A Difference Caring for Homeless Mentally ill Women: The Banyan Experience (Evaluation report), Chennai: The Banyan.

Kuruvilla, A. \& Jacob, K.S. (2007). Poverty, social stress and mental health. Indian Journal of Medical Research, 126: 273-378.

Lam, J.A. and Rosenheck, R. (2000). The Effect of Victimization on Clinical Outcomes of Homeless Persons With Serious Mental Illness , Psychiatric Services, . 49: 678-683.

Mental Health Act (1987). Government of India. New Delhi. 
Murali T. \& Rao K. (2004). Psychiatric Rehabilitation in India: Issues and challenges.

Agarwal S.P., Goel D.S., Ichhpujani R.L., Salhan R.N. \& Shrivastava, S. (Ed.) Mental Health - An Indian Perspective 1946- 2003. New Delhi: Elsevier, 152-160.

Murali, T. \& Rao, K. (2004). Psychiatric Rehabilitation in India: Issues and challenges. In: Agarwal S.P., Goel D.S., Ichhpujani R.L., Salhan R.N., Shrivastava S (Ed.) Mental Health - An Indian Perspective 1946- 2003. New Delhi: Elsevier, 152-160.

Murali, T. (2002). From the secretary's desk. World Association for psychosocial rehabilitation Indian chapter Bulletin, 6- 5.

Murphy, H. and Murphy, E. K. (2006). Comparing quality of life using the World Health Organization Quality of Life measure (WHOQOL-100) in a clinical and non-clinical sample: Exploring the role of self-esteem, self-efficacy and social functioning, Journal of Mental Health, 15(3): 289300. doi./10.1080/09638230600700771.

National Workshop on Mental Illness and Homelessness (2004). Chennai. The Banyan. August 25-27.

NHRC (1999). Quality assurance in mental health. New Delhi. National Human Rights Commission.

NHRC (2008). Mental health Care and Human Rights. New Delhi. National Human Rights Commission.

Radhakrishnan. V.K, (2002). Current Issues of Psychiatric Rehabilitation. In PCSJ (2002). Palluruthy Relief Settlement Day Celebrations Souvenir. Kochi: PCSJ

Rehabilitation Council of India Act (1992). Government of India. New Delhi.

Rosenson M. K., Kasten A. M., \& Kennedy M. E. ( 1988). Expanding the role of families of the mentally ill. In J. S. McNeil \& S. E. Weinstein (Eds.), Innovations: In health care practice (pp. 116-133). Silver Spring, MD: National Association of Social Workers.

Ruggeri, M., Warner, R., Bisoffi, G. \& Fontecedro, L.(2001). Subjective and objective dimensions of quality of life in psychiatric patients: a factor analytical approach: The South Verona Outcome Project 4. British Journal of Psychiatry, 178, 268 -275. doi/10.1192/bjp.178.3.268.

Santhosh, Joseph. \& Anish, K. R. (2006). An Indian Model of Low Cost Community Based Rehabilitation of Homeless Mentally Ill. Paper presented during Meet The Expert session of IX World Congress, 
World Association of Psychosocial Rehabilitation, Athens, Greece, 1215 , October.

Sheth, H. C. (2005). Common Problems in Psychosocial Rehabilitation. International Journal of Psychosocial Rehabilitation. 10(1), 53-60.

Suresh, B.M., Nagaraja, D., (2008). Mental Health Legislation: An Indian Perspective. In: NHRC (2008). Mental health Care and Human Rights. New Delhi: National Human Rights Commission.

WHO (2004). The world health report 2004. Changing history. Geneva. World Health Organization.

World Health Organization (2001). The World Health Report. Mental Health. New Understanding, New Hope. Geneva

World Health Organization (2011). The Mental Health Atlas. Geneva 